\title{
Determination of Optimal Parameters for Diffusion Bonding of Semi-Solid Casting Aluminium Alloy by Response Surface Methodology
}

\author{
Somsak Kaewploy ${ }^{a}$, Chaiyoot Meengam ${ }^{b}$ \\ Program of Engineering, Faculty of Industrial Technology, Songkhla Rajabhat University, Songkhla, Thailand 90000.
}

\begin{abstract}
Liquid state welding techniques available are prone to gas porosity problems. To avoid this solid state bonding is usually an alternative of preference. Among solid state bonding techniques, diffusion bonding is often employed in aluminium alloy automotive parts welding in order to enhance their mechanical properties. However, there has been no standard procedure nor has there been any definitive criterion for judicious welding parameters setting. It is thus a matter of importance to find the set of optimal parameters for effective diffusion bonding. This work proposes the use of response surface methodology in determining such a set of optimal parameters. Response surface methodology is more efficient in dealing with complex process compared with other techniques available. There are two variations of response surface methodology. The one adopted in this work is the central composite design approach. This is because when the initial upper and lower bounds of the desired parameters are exceeded the central composite design approach is still capable of yielding the optimal values of the parameters that appear to be out of the initially preset range. Results from the experiments show that the pressing pressure and the holding time affect the tensile strength of jointing. The data obtained from the experiment fits well to a quadratic equation with high coefficient of determination $\left(\mathrm{R}^{2}=94.21 \%\right)$. It is found that the optimal parameters in the process of jointing semi-solid casting aluminium alloy by using diffusion bonding are the pressing pressure of $2.06 \mathrm{MPa}$ and 214 minutes of the holding time in order to achieve the highest tensile strength of $142.65 \mathrm{MPa}$.
\end{abstract}

\section{Introduction}

Currently, several methods of welding processes are available. Selection of the appropriate welding process is essential. The selection depends on the characteristics of products or of the particular industrial group. The welding or jointing process that causes melting at the welding line is the so called liquid state welding. On the other hand, the non-fusion welding or solid state welding is such that heat at the welding line has a temperature below the melting point of the material [1]. There are many methods of solid state welding such as friction stir welding [2], friction welding [3] and diffusion bonding [4] etc. Solid state welding results in a specimen without gas porosities after welding, [5] however, aluminium welding has the possibility of this problem occurring, especially, in the automotive industry which uses lightweight materials in the production of automobile parts. Semi-solid casting is another method that can be used to increase the mechanical properties of materials, especially, the aluminum applied in the automotive industry such as grades 6061,356 and 7075 . The welding of these alloy grades is difficult. However, the jointing of diffusion bonding enables the reduction of these welding problems because it causes the jointed base metals to be attached together at temperatures lower than the melting temperature of that metal while the base metal is still in the solid state [6]. The base metals join together in the heat which has a temperature below the melting point based on the principle of atom diffusion; the metal is heated with low pressing pressure while jointing and then takes time to join together. Factors affecting the diffusion bonding process are contact pressure, holding time, temperature, atmosphere, and other parameters, therefore, in the process of jointing, it is necessary to set up optimal parameters in order to reduce the amount of energy consumption during the welding process.

The Response surface methodology (RSM) is a mathematical and statistical method which is useful in modelling and analyzing the problems using second order polynomial or quadratic models $[7,8]$. This model shows the response to various parameters in order to find out an optimal value of the output [9]. Central composite design (CCD) is an approach of response surface methodology which is very flexible when the initial upper and lower bounds of the desired parameters are exceeded the Central composite design approach is still capable of yielding the optimal values of the parameters that appear to be out of the initially preset range [10]. This study is intent on investigating factors affecting tensile strength, to determine the optimal parameters in butt-joint diffusion bonding process of semi-solid casting aluminium alloy in order to achieve maximum tensile strength using central composite design approach of RSM.

\footnotetext{
${ }^{a}$ Corresponding author: Somsakkp@hotmail.com; ${ }^{b}$ Chaiyoot.me@skru.ac.th
} 


\section{Application of RSM for Obtaining Optimal Welding Parameters}

It is well known that most response surface obtained from experimental data are of regular shape and representable mathematically $[11,12,13]$. This is of great interest in terms of resource saving. That is to say the use of response surface methodology certainly reduces the amount of data required in response surface construction. Experiment can be carried out with greater cost saving, less time consuming and much lesser consumption of energy and other resources. Therefore response surface methodology is adopted as a mathematical tool in this study. The central composite design approach of response surface methodology is a technique of preference due to its capability in yielding optimal parameters even though their values may appear out of the initially preset range before the experiment is carried out. Details of central composite design implementation are given in the next section.

\section{Material and Experimentation}

\subsection{Material and Equipments.}

1) The experimental material is graded 356 aluminium alloy produced from a semi-solid squeeze casting using gas induced semi-solid (GISS) technique [14]. This graded 356 aluminium alloy is made into 78 pieces of smooth surfaced cylindrical shape specimen of diameter $11 \mathrm{~mm}$, length $35 \mathrm{~mm}$. Next, all specimen undergoes T6 heat treatment by increasing the heat from room temperature to $540^{\circ} \mathrm{C}$ in 1.0 hours. This desired temperature is held further for 8 hours. After that all specimen are dipped into the water and left for artificial aging at $165^{\circ} \mathrm{C}$ for 12 hours.

2) A low-temperature LINDBERG/ BLUE furnace is used for $\mathrm{T} 6$ heat treatment before welding. It can be programmed to perform several working steps, and at the end of the order cycle it shuts down automatically.

3) Tensile testing machine of testomatic brand, with maximum tensile strength $150 \mathrm{~N}$.

4) Machine tools for specimen preparation.

\subsection{Diffusion Bonding.}

Welding of semi-solid casting aluminium alloy using bonding diffusion is conducted by preparing the two jointed base metals under various levels of pressing pressure control conditions according to the experimental plan. The jointed metals are lathed by machine and ground with sand paper to remove the aluminium oxide film, dirt, and grease on the surface. Before welding, acetone is used to clean part of the surface to be welded, dried by air blowing, and put into the stove. The metals are clamped as shown in Fig. 1. Finally, they are pressed by predetermined compressive pressure while argon gas is blown into the furnace at a flow rate of 4 litters per minute and at a temperature of $495^{\circ} \mathrm{C}$. The increase of the jointing temperature are divided into 3 steps as follows: firstly, the temperature rises up to $495^{\circ} \mathrm{C}$ in 2 hours and being kept constant for 15 minutes in order to maintain furnace life and reduce specimen deformation due to high temperatures. After that the temperature is kept at $495^{\circ} \mathrm{C}$ to cause diffusion and form jointing between the two base metals (specimens) until reaching the holding time as in the experimental plan. The furnace temperature then declines until it reached room temperature in 2 hours (Fig.2). Then the welded specimens of 356 semi-solid casting aluminium alloys (SSM) are prepared for tensile testing. The specimens are shaped into standard sizes; ASTM (A370) [15], perpendicular to the welding line, and tensile strength are tested.

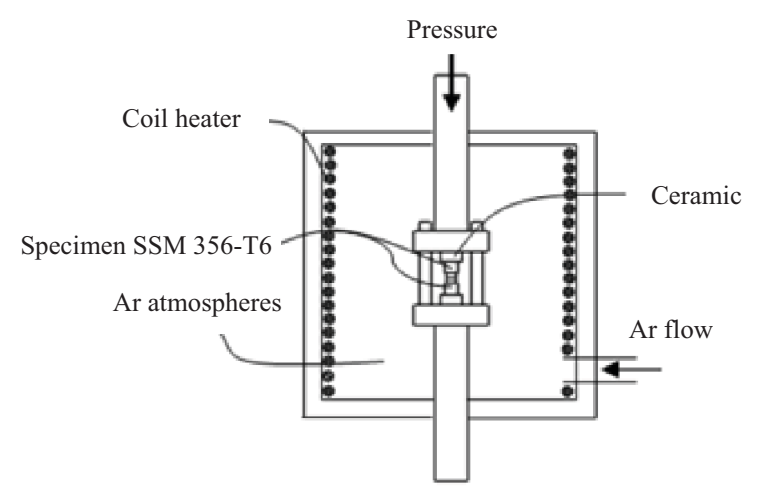

Fig. 1: Schematic representation of diffusion bonding process

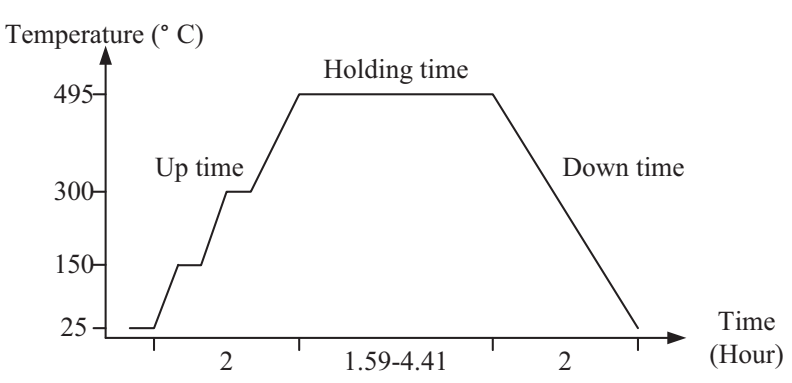

Fig. 2: Sequence of temperature for diffusion bonding

\section{Results and Discussion}

\subsection{Central Composite Design Approach of RSM.}

Two factors affecting the tensile strength, namely the pressing pressure and holding time which are important in constructing the response surface by central composite design approach. The levels of the two factors are based on the standard of related researches, preliminary experiments, and limitations of tools used in the experiment. There were 5 levels on condition 3 replicates of experimental factors: low (-1), middle $(0)$ high $(+1)$ and additional alpha as +1.414 and -1.414 , as shown in Table 1 . The numbers of the experiments were 39 in total. The analysis was conducted for regression analysis and model appropriate as follows. 
Table 1. Factors and each factor level for central composite design

\begin{tabular}{lccccc}
\hline \multirow{1}{*}{ Factor } & \multicolumn{5}{c}{ Level } \\
\cline { 2 - 6 } & $\begin{array}{c}\text {-Alpha } \\
(-1.414)\end{array}$ & -1 & 0 & +1 & $\begin{array}{l}+ \text { Alpha } \\
(+1.414)\end{array}$ \\
\hline $\begin{array}{l}\text { Pressure: A } \\
\begin{array}{l}\text { MPa) } \\
\text { Holding } \\
\text { Time: B (Hr) }\end{array}\end{array}$ & 0.69 & 1.00 & 1.75 & 2.50 & 2.81 \\
\hline
\end{tabular}

(1) Model adequacy checking was used to find out the accuracy of the analyzed data in order to verify the model based on the principle of $\varepsilon_{i j} \sim \operatorname{NID}\left(0, \sigma^{2}\right)$ [16]. The following assumptions, as shown in Fig.3, are considered in the checking process: (a) data are normally distributed because the normal probability plot is close to a straight line and the p-value is more than 0.05. (b) data have an independent distribution, because the distribution of residuals is independent. There are no outlier points, larger residuals or exact patterns. (c) data show stability of variance because residues are randomly distributed. Thus this data set is fit for further analysis.

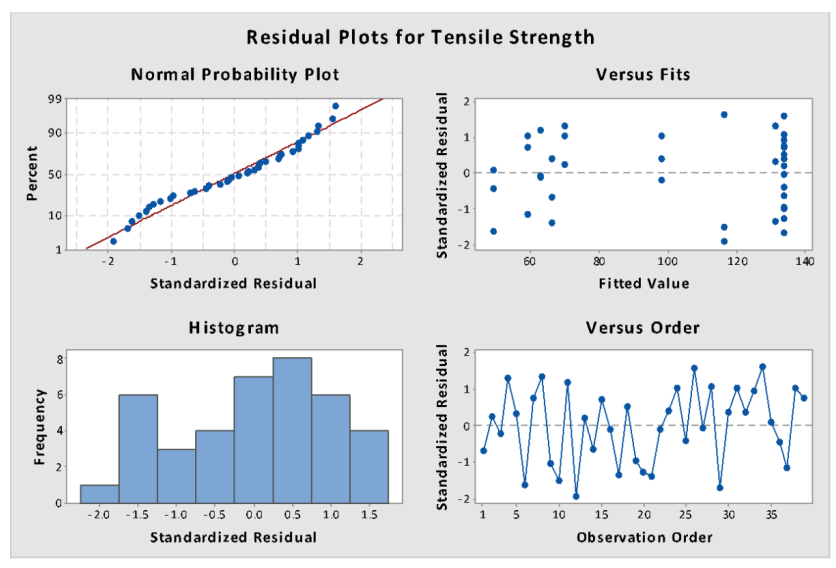

Fig. 3: Graphical model adequacy checking

(2) Regression analysis of central composite design in experimental designs. The regression analysis in Table 2 indicates that factors affecting the tensile strength of SSM aluminium alloy using the diffusion bonding process with a p-value less than the 0.05 significant level are jointing pressing pressure (A), and holding time (B), the square term of the pressing pressure $\left(A^{*} A\right)$, the square term of the holding time $\left(\mathrm{B}^{*} \mathrm{~B}\right)$, and the interaction between the pressing pressure and holding time $(\mathrm{A} * \mathrm{~B})$. When considering lack of fit, it has a p-value of 0.159 which is more than 0.05 as shown in Table 3. It means that equation 1 's construction has adequate precision in forecasting the tensile strength of semi-solid casting aluminium alloy using diffusion bonding. The coefficient of determination $\mathrm{R}^{2}$ is $94.21 \%$, meaning that the total variation of the tensile strength of $100 \%$ can be predicted by this equation (1) with up to $94.21 \%$ the graphic model adequacy checking.

Tensile strength $=-232.0+156.2 \mathrm{~A}+120.4 \mathrm{~B}$

$$
-53.6 \mathrm{~A}^{2}-22.18 \mathrm{~B}^{2}+18.11 \mathrm{AB}
$$

Table 2. Regression analysis for central composite experimental design

\begin{tabular}{|c|c|c|c|c|}
\hline Term & Coef & SECoef & $\mathrm{T}$ & $P$ \\
\hline Constant & 133.86 & 2.34 & 57.21 & 0.000 \\
\hline Pressure & 17.21 & 1.85 & 9.32 & 0.000 \\
\hline Holding Time & 19.00 & 1.85 & 10.28 & 0.000 \\
\hline Pressure*Pressure & -30.15 & 1.98 & -15.22 & 0.000 \\
\hline Holding Time* & -22.18 & 1.98 & -11.20 & 0.000 \\
\hline Holding Time & & & & \\
\hline Pressure*Holding Time & 13.59 & 2.61 & 5.20 & 0.000 \\
\hline $\mathrm{S}=9.05175 \quad \mathrm{R}-\mathrm{S}$ & $=94.21 \%$ & \multicolumn{3}{|c|}{$\mathrm{R}-\mathrm{Sq}(\mathrm{adj})=93.34 \%$} \\
\hline
\end{tabular}

Table 3. Variant analysis of tensile strength obtained from diffusion bonding

\begin{tabular}{lccccc}
\hline \multicolumn{1}{c}{ Source } & DF & Seq SS & Adj MS & F & P \\
\hline Regression & 5 & 44029.7 & 8805.9 & 107.48 & 0.000 \\
Linear & 2 & 15775.2 & 7887.6 & 96.27 & 0.000 \\
Square & 2 & 26039.6 & 13019.8 & 158.91 & 0.000 \\
Interaction & 1 & 2214.9 & 2214.9 & 27.03 & 0.000 \\
Residual E & 33 & 2703.8 & 81.9 & & \\
Lack-of-Fit & 3 & 422.8 & 140.9 & 1.85 & 0.159 \\
Pure Error & 30 & 2281.0 & 76.0 & & \\
\hline \multicolumn{1}{c}{ Total } & 38 & 46733.5 & & & \\
\hline
\end{tabular}

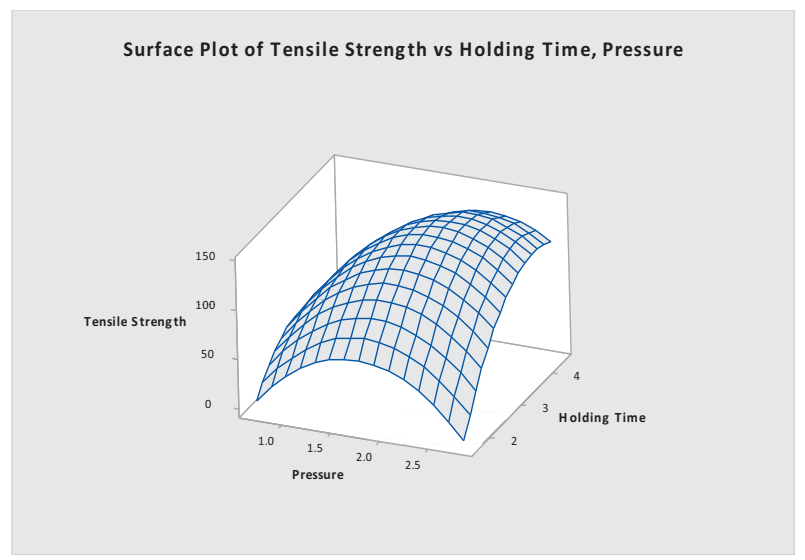

Fig. 4: The response surface plot of tensile strength

The response surface plot in Fig. 4 shows the impact of pressing pressure and holding time on tensile strength. When the jointing pressing pressure and holding time increases, the tensile strength increases. It can be said that the aluminium alloy undergoing $\mathrm{T} 6$ heat treatment has certain residual strain after heating. The voids decrease because two base metal surfaces are attached. As a result, the specimens have less deflection and high strength. The response surface plot is illustrated in the form of a contour plot as in Fig. 5. It can be explained by saying that the graphic characteristic is nonlinear. The inner oval area has the highest strength at $125 \mathrm{MPa}$, and the outer oval area shows lower tensile strength values of 100,75 , 50,25 , and $0 \mathrm{MPa}$ respectively. 


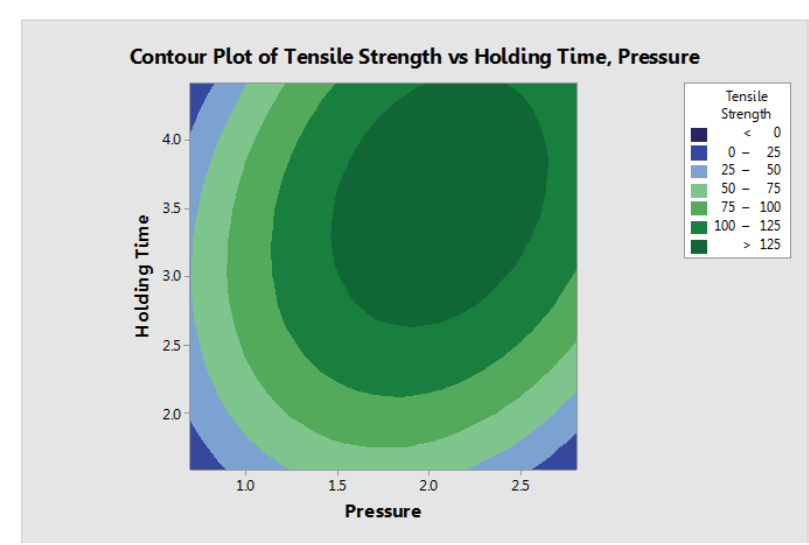

Fig. 5: The contour plot of tensile strength

To determine the optimal parameters in order to reach the highest tensile strength, the response optimization function is used to determine the optimal parameters and measure the overall satisfaction of the response (Composite desirability; D), ranging between $0-1$. If the value of $\mathrm{D}$ is 1 , it means that the response output is completely satisfactory. From the analysis of response optimization, the factor level suited for semi-solid casting aluminium alloy using diffusion bonding process is shown in Fig. 6. The optimal parameters of this process, which provides the highest tensile strength, are jointing pressing pressure of $2.06 \mathrm{MPa}$ and a holding time of 3.56 hours or 214 minutes. The response output; a tensile strength of $142.65 \mathrm{MPa}$ with full optimum desirability at 1.0 is obtained.

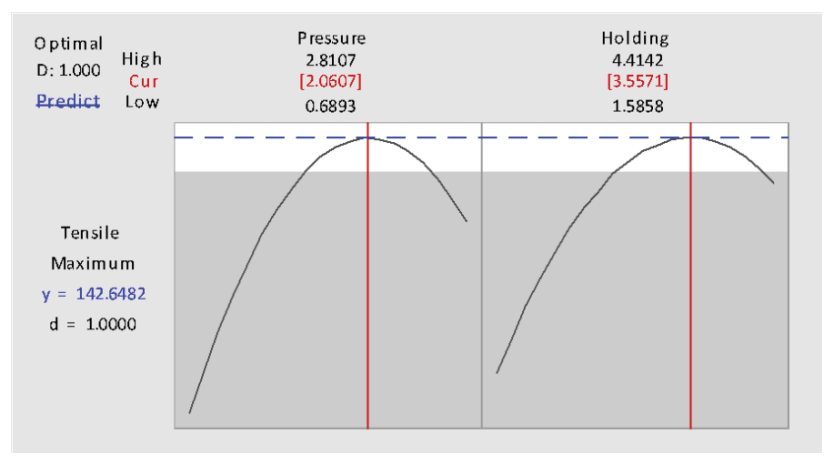

Fig. 6: The analysis of optimal parameters in diffusion bonding process

\subsection{Confirmation test.}

Confirmation of the result can be performed by employing the regression equation to predict tensile strength and conducting the experiment to find the appropriate parameters in the diffusion bonding process of jointing semi-solid aluminium alloy. From experimental data, it is found that the appropriate parameters are the adjusted pressing pressure of 2.06 $\mathrm{MPa}$, the holding time of 214 minutes and 20 replications. Then results are compared to the actual experimental values. The confirmation test has a p-value of 0.463 which is better than the 0.05 level of significance. It can be concluded that it is statistically insignificant. After the predictive equation is confirmed by comparing it with the value measured from the experiment, the result shows that it has minor error. This equation can be used to predict the tensile strength in jointing semi-solid aluminium alloy using diffusion bonding.

\section{Conclusions}

The experiments on jointing of semi-solid casting aluminium alloy using diffusion bonding, has demonstrates that the central composite design approach of the response surface methodology can be used in determining optimal parameters for diffusion bonding. It is found from the experiment that factors affecting jointing semi solid casting aluminium alloy using diffusion bonding process are the pressing pressure of $2.06 \mathrm{MPa}$ and holding time of 214 minutes. The experimental results can be used to construct regression equations to predict the tensile strength values formed from jointing SSM aluminium alloy using diffusion bonding. The estimated tensile strength values and the relationship between varying factors can be expressed as: fitted tensile strength $=-232.0+156.2 \mathrm{~A}+120.4 \mathrm{~B}-$ $53.6 \mathrm{~A}^{2}-22.18 \mathrm{~B}^{2}+18.11 \mathrm{AB}$, which have the coefficient of determination $(94.21 \%)$. After confirmation tests the results of average tensile strength from experiments are close to the tensile strength values estimated from the predictive equation of the tensile strength with a 95\% confidence interval.

\section{Acknowledgements}

The author would like to thank the program of engineering, the faculty of industrial technology, Songkhla Rajabhat University, for their kindness and support in providing materials, equipment and facilities for this research work.

\section{References}

1. K. Kitazono, A. Kitajima, E. Sato, Solid-state diffusion bonding of closed-cell aluminum foams, Mat. Sci. Eng. A. 327 (2002) 128-132.

2. G. Liu, L.E. Murr, C. Niou, J.C. McClure, F.R. Vega, Microstructural aspects of the friction stir welding of 6061-T6 aluminum, Scripta Mater. 37 (1997) 355-361.

3. K. Boonseng, C. Meengam, S. Chainarong, P. Muangjunburee, Microstructure and Hardness of Friction Welded SSM 356 Aluminium Alloy, AMR. 887-888 (2014) 1273-1279.

4. A.S. Zuruzi, H. Li, G. Dong, Effects of surface roughness on the diffusion bonding of Al alloy 6061 in air, Mat. Sci. Eng. A. 270 (1999) 244-248. 
5. S. Benavides, Y. Li, L.E. Murr, D. Brown, J.C. McClure, Low temperature Friction Stir welding of 2024 aluminum, Scripta Mater. 41 (8) (1999) 809815.

6. Y.W. Horng, L. Shyong W. JianYih, Solid-state bonding of iron-based alloys, steel-brass andaluminum alloys, J. Mater. Process. Technol. 75 (1998) 173-179.

7. E.P. Box, R. George Norman and R. Draper, Empirical Model-Building and Response Surface, John Wiley and Sons, New York, 1987.

8. H. Myers, Raymond, Response Surface Methodology, Edwards Brothers, USA, 1976.

9. D.C. Montgomery, Designing and analysis of experiments, 5th ed., John Wiley \&Sons Inc. New York, 2000.

10. D.C. Montgomery, G.C. Runger, N.F. Hubele, Engineering statistics. 4th ed., John Wiley \&Sons Inc. New York, 2000.

11. M.J. Fernandus, T. Senthikumar, V. Balasubramanian, S. Rajakumar, Optimising diffusion bonding parameters to maximize the strength of AA6061 aluminium and AZ31B magnesium alloy joints, Mater. Design. 33 (2012) 31-41.

12. G. Elatharasan, V.S. Kumar, An experimental analysis and optimization of process parameter on friction stir welding of AA 6061-T6 aluminum alloy using RSM, Procedia Eng. 64 (2013) 1227-1234.

13. N. Kiaee, M. Aghaie-Khafri, Optimization of gas tungsten arc welding process by response surface, Mater. Design. 54 (2014) 25-31.

14. J. Wannasin, S. Junudom, T. Rattanochaikul, M.C. Flemings, Development of the Gas Induced SemiSolid Metal Process for Aluminum Die Casting Applications, SSP. 141 (2008) 97-102.

15. C.S. Lee, H. Li, R.S. Chandel, Vacuum-free diffusion bonding of aluminium metal matrix composite, J. Mater. Process. Technol. 89-90 (1999) 326-330.

16. A.M. Hassan, O.M. Bataineh and K.M. Abed, The effect of time and temperature on the precipitation behavior and hardness of Al-4wt \% Cu alloy using design of experiments, J. Mater. Process. Technol. 204 (2008)342-349. 